\title{
Granulocyte colony-stimulating factor treatment in chronic Chagas disease: preservation and improvement of cardiac structure and function
}

\author{
Simone G. Macambira, ${ }^{, \dagger}$ Juliana F. Vasconcelos, ${ }^{*}$ Claudio R. S. Costa, ${ }^{*}$ \\ Wilfried Klein, ${ }^{\ddagger}$ Ricardo S. Lima, ${ }^{*}$ Patrícia Guimarães, ${ }^{*}$ Daniel T. A. Vidal,* \\ Lucas C. Mendez, ${ }^{*}$ Ricardo Ribeiro-dos-Santos, ${ }^{*, \S}$ and Milena B. P. Soares $*, \S, 1$ \\ *Centro de Pesquisas Gonçalo Moniz, Fundação Oswaldo Cruz, Salvador, Bahia, Brazil; ${ }^{\dagger}$ Instituto de \\ Biofísica Carlos Chagas Filho, Universidade Federal do Rio de Janeiro, Rio de Janeiro, Brazil; \\ ${ }^{\ddagger}$ Instituto de Biologia, Universidade Federal da Bahia, Salvador, Bahia, Brazil; and ${ }^{\S}$ Hospital São \\ Rafael, Salvador, Bahia, Brazil
}

ABSTRACT This study investigates the effects of granulocyte colony-stimulating factor (G-CSF) therapy in experimental chronic chagasic cardiomyopathy. Chagas disease is one of the leading causes of heart failure in Latin America and remains without an effective treatment other than cardiac transplantation. C57BL/6 mice were infected with $10^{3}$ trypomastigotes of Trypanosoma cruzi, and chronic chagasic mice were treated with G-CSF or saline (control). Evaluations following treatment were functional, immunological, and histopathological. Comparing hearts of G-CSFtreated mice showed reduced inflammation and fibrosis compared to saline-treated chagasic mice. G-CSF treatment did not alter the parasite load but caused an increase in the number of apoptotic inflammatory cells in the heart. Cardiac conductance disturbances in all infected animals improved or remained stable due to the G-CSF treatment, whereas all of the saline-treated mice deteriorated. The distance run on a treadmill and the exercise time were significantly greater in G-CSFtreated mice when compared to chagasic controls, as well as oxygen consumption $\left(\dot{V} \mathrm{O}_{2}\right)$, carbon dioxide production $\left(\dot{V} \mathrm{CO}_{2}\right)$, and respiratory exchange ration (RER) during exercise. Administration of G-CSF in experimental cardiac ischemia had beneficial effects on cardiac structure, which were well correlated with improvements in cardiac function and whole animal performance.-Macambira, S. G., Vasconcelos, J. F., Costa, C. R. S., Klein, W., Lima, R. S., Guimarães, P., Vidal, D. T. A., Mendez, L. C., Ribeiro-dos-Santos, R., Soares, M. B. P. Granulocyte colony-stimulating factor treatment in chronic Chagas disease: preservation and improvement of cardiac structure and function. FASEB J. 23, 3843-3850 (2009). www.fasebj.org

Key Words: chagasic cardiomyopathy $\cdot$ inflammation $\cdot$ arrhythmias $\cdot$ treadmill performance

Chagas disease, CAUSED By Trypanosoma cruzi infection, is one of the main causes of death due to heart failure in
Latin American countries. About $25 \%$ of chagasic individuals develop a chronic chagasic cardiomyopathy (CChC), the most severe form of disease. The chemotherapy used in chagasic patients is highly toxic and has limited efficacy, especially in the chronic disease. The unique definitive treatment for CChC aggravated by severe heart failure is heart transplantation.

Studies establishing therapies to restore the cardiac function using stem cells or the administration of growth factors have been developed. Bone marrow stem cells (BMSCs) differentiate into cardiomyocytes and endothelial cells and may participate in the regeneration of cardiac lesions (1-4). Granulocyte colonystimulating factor (G-CSF) increased the number of peripheral granulocytes (5) and induced the mobilization of BMSCs to the periphery (6). This property and regenerative capacity of BMSCs justify the efforts to prove the efficacy of this therapy.

The beneficial effects of G-CSF in the treatment of cardiac ischemia lesions have been shown (7-9). The therapeutic use of G-CSF is attractive because it is already employed in clinical practice, has mild side effects, and is a less invasive treatment than bone marrow aspiration and cell transplantation. We have previously shown that therapy with BMSCs decreases heart inflammation and fibrosis in experimental CChC (10). Here, we investigated the effects of G-CSF on cardiac alterations in a model of CChC.

\section{MATERIALS AND METHODS}

Animals

Two-month-old male C57BL/6 mice, raised and maintained in the animal facilities at the Gonçalo Moniz

\footnotetext{
${ }^{1}$ Correspondence: Milena Botelho Pereira Soares, Centro de Pesquisas Gonçalo Moniz, Fundação Oswaldo Cruz. 121, Rua Waldemar Falcão, Candeal, Salvador, Bahia, Brazil, 40.296-710. E-mail: milena@bahia.fiocruz.br doi: 10.1096/fj.09-137869
} 
Research Center (Fiocruz, Rio de Janeiro, Brazil) were used in the experiments, and were provided with rodent diet and water ad libitum. All animals were sacrificed under anesthesia by intraperitoneal injection of xylazine at 10 $\mathrm{mg} / \mathrm{kg}$ body wt and ketamine at $100 \mathrm{mg} / \mathrm{kg}$ body wt, and handled according the National Institutes of Health guidelines for ethical use of laboratory animals.

\section{T. cruzi infection and treatment with G-CSF}

Mice were infected by intraperitoneal injection of 1000 trypomastigote forms of Colombian strain T. cruzi (11) obtained by in vitro infection of LCC-MK2 cell line. Parasitemia was evaluated at different time points after infection by counting the number of trypomastigotes in peripheral blood aliquots (12). Groups of chronic chagasic mice (6 mo after infection) were treated with human recombinant G-CSF (Granulokine 30; Hoffman la Roche, Switzerland) with 200 $\mu \mathrm{g} / \mathrm{kg} / \mathrm{d}$ during 5 consecutive days with 3 cycles of administration or with $5 \%$ glucose saline solution in the same regimen.

\section{Histopathological analysis}

Hearts from G-CSF-treated mice and untreated controls were removed and fixed in buffered $10 \%$ formalin. Sections of paraffin-embedded tissue were stained by standard hematoxylin-and-eosin (H\&E) and Sirius red staining for evaluation of inflammation and fibrosis, respectively, by optical microscopy. Images were digitized using a color digital video camera (CoolSnap, Montreal, QC, Canada) adapted to a BX41 microscope (Olympus, Tokyo, Japan). The images were analyzed using Image Pro 5.0 (Media Cybernetics, San Diego, CA, USA), to integrate the number of inflammatory cells counted by area. Ten fields per heart were counted from every mouse of each group.

\section{Parasite quantification by immunofluorescence analysis}

Frozen heart sections (5 $\mu \mathrm{m}$ thick) were prepared in a cryostat in poly-L-lysine-coated slides and fixed with cold acetone. Sections were incubated with PBS 5\% BSA for 30 min, followed by overnight incubation with rat serum anti- $T$. cruzi (1:400). After washing with PBS, sections were incubated for $1 \mathrm{~h}$ with FITC-conjugated rabbit anti-rat IgG 1:100 (Sigma, St. Louis, MO, USA). Sections were washed 3 times, counterstained with Evans blue, and mounted with Vectashield (Vector, Burlingame, CA, USA). Images were digitized using a color digital video camera (DP-70; Olympus) adapted to an AX-70 microscope (Olympus). The images were analyzed using Image Pro, and the numbers of parasite foci were counted (10 fields/heart, 5 mice/group) and integrated by area.

\section{Stroma-derived factor-1 (SDF-1) assessment in total-protein heart extracts}

Heart proteins were extracted at $100 \mathrm{mg}$ of tissue/ml of PBS to which $0.4 \mathrm{M} \mathrm{NaCl}, 0.05 \%$ Tween 20 and protease inhibitors (0.1 mM PMSF, $0.1 \mathrm{mM}$ benzethonium chloride, $10 \mathrm{mM}$ EDTA, and $20 \mathrm{KI}$ aprotinin $\mathrm{A} / 100 \mathrm{ml}$ ) were added. The samples were centrifuged for $10 \mathrm{~min}$ at $3000 \mathrm{~g}$, and the supernatant was frozen at $-70^{\circ} \mathrm{C}$ for later quantification. SDF-1 levels were estimated using a commercially available Immunoassay ELISA kit (R\&D Systems, Minneapolis, MN, USA), according to the manufacturer's guidelines.

\section{Apoptosis assay}

Apoptosis in heart sections fixed using $4 \%$ formaldehyde was evaluated by terminal uridine deoxynucleotidyl transferase dUTP nick end labeling (TUNEL) assay, performed using in situ DeadEnd Colorimetric TUNEL System kit (Promega, Madison, WI, USA), according to the manufacturer's instructions. Images were digitized, and quantitative analysis was performed using Image Pro. Results were expressed as the number of positive cells per square millimeter of 10 sections from 4 animals/group. The positive controls were nucleasetreated slides.

\section{ECG analysis}

Electrocardiography was performed using the Bio Amp PowerLab System (PowerLab 2/20; ADInstruments, Castle Hill, NSW, Australia), recording the bipolar lead I. All animals were anesthetized by intraperitoneal injection of xylazine at $10 \mathrm{mg} / \mathrm{kg}$ body weight and ketamine at $100 \mathrm{mg} / \mathrm{kg}$ body weight to obtain the records. All data were acquired for computer analysis using Chart 5 for Windows (PowerLab). Records were bandpass filtered (1 to $100 \mathrm{~Hz}$ ) to minimize environmental signal disturbances. The sampling rate was 1 $\mathrm{kHz}$. The ECG analysis included heart rate, PR interval, $\mathrm{P}$ wave duration, QT interval, QTc, and arrhythmias. Wave durations (ms) and heart rate were calculated automatically by the software after the cursors were placed. The QTc was calculated as the ratio of QT interval by square roots of RR interval.

\section{Treadmill}

A motor-driven treadmill chamber for one animal (LE 8700; Panlab, Barcelona, Spain) was used to exercise the animals. The speed of the treadmill and the intensity of the shock (mA) were controlled by a potentiometer (LE 8700 treadmill control; Panlab). Room air was pumped into the chamber at a controlled flow rate $(700 \mathrm{ml} / \mathrm{min})$ by a chamber air supplier (Oxylet LE 400; Panlab). Outflow was directed to an oxygen and carbon dioxide analyzer (Oxylet 00; Panlab) to measure consumption of oxygen $\left(\dot{V} \mathrm{O}_{2}\right)$, production of carbon dioxide $\left(\dot{V} \mathrm{CO}_{2}\right)$, and the respiratory exchange ratio (RER). The mean room temperature was maintained at $21 \pm$ $1^{\circ} \mathrm{C}$. After an adaptation period of $40 \mathrm{~min}$ in the treadmill chamber, the mice exercised at 5 different velocities (7.2, 14.4, 21.6, 28.8 and $36.0 \mathrm{~m} / \mathrm{min}$ ), with increasing velocity after $10 \mathrm{~min}$ of exercise at a given speed. Velocity was increased until the animal could no longer sustain a given speed and remained $>10 \mathrm{~s}$ on an electrified stainless-steel grid, which provided an electrical stimulus to keep the mice running. After reaching exhaustion, animals were left undisturbed in the treadmill chamber for $30 \mathrm{~min}$. $\dot{V} \mathrm{O}_{2}$ and $\dot{V} \mathrm{CO}_{2}$ were determined using the program Metabolism for 2 channel PowerLab (ADInstruments), analyzing the last $5 \mathrm{~min}$ recorded at rest and at each speed. During recovery, $\dot{\mathrm{VO}}_{2}$ and $\dot{V} \mathrm{CO}_{2}$ were determined during a 3-min period following immediately after cessation of exercise (recovery 1; exhaustion) and at the end of the 30-min recovery period (recovery 2). Subsequently, RER was calculated. Total running distance and running time were recorded. To determine peak oxygen consumption, we measured the greatest value in oxygen consumption shown by each mouse during exercise.

\section{Statistical analyses}

All continuous variables are presented as means \pm SE. Morphometric and cytokine levels were analyzed using 1-way 
ANOVA, followed by Newman-Keuls multiple-comparison test. Cardiopulmonary parameters were analyzed using Student's $t$-test and Mann Whitney $U$ test with Prism 3.0 (GraphPad Software, San Diego, CA, USA). Degree of severity was analyzed using a 2-way ANOVA, followed by a Bonferroni post-test. Treadmill data were analyzed applying a repeated-measures 1-way ANOVA, followed by an all-pairwise multiple comparison procedure (Student-Newman-Keuls method) using Prism 3.0. All differences were considered significant at values of $P \leq 0.05$.

\section{RESULTS}

\section{Decreased myocarditis and fibrosis after G-CSF treatment}

A marked decrease in the number of inflammatory cells was observed 2 mo after G-CSF treatment, compared with saline-treated chagasic mice (Fig. 1A, C). Morphometric analysis showed a significant reduction in the number of inflammatory cells after G-CSF treatment (Fig. 2A). In addition, hearts of G-CSF-treated mice had a reduced area of fibrosis (Fig. $1 B, D$ ), statistically different from saline-treated mice (Fig. 2B). The number of inflammatory cells undergoing apoptosis was $\sim 7$-fold greater in hearts of G-CSF-treated mice compared to those of saline-treated mice (Fig. $2 C ; P<0.0001$ ). The levels of the chemokine SDF-1 (CXCL2) in hearts of saline-treated, but not of G-CSF-treated mice, were significantly higher than those of normal mice (Fig. 2D). Hearts from both saline- and G-CSF-treated mice had similar numbers of parasite foci 2 mo after therapy $\left(2.4 \pm 0.4\right.$ and $2.0 \pm 0.6$ parasite foci $/ \mathrm{mm}^{2}$, respectively; $P<0.05)$.

G-CSF treatment ameliorates cardiac electrogenesis in chronic chagasic mice

All infected mice showed severe cardiac conduction disturbances in ECG records, such as AV blockage, intraventricular conduction disturbances, and abnormal cardiac rhythm 6 mo after infection, compared to normal mice (Fig. 3). In saline-treated mice $(n=7)$, none improved cardiac function, and 5 became worse after therapy. In contrast, in the G-CSF-treated group $(n=6), 2$ animals improved cardiac conduction (Fig. 4), and 4 had no alterations (Fig. 3).

\section{G-CSF treatment improves exercise capacity}

Among the saline-treated infected mice, only 2 of 6 were able to keep up with a belt speed of up to 14.4 $\mathrm{m} / \mathrm{min}$. The other 4 untreated infected mice were not able to run on the treadmill. All animals in the G-CSF-treated group $(n=7)$ and in the normal control group $(n=10)$ were able to exercise on the treadmill. All of the G-CSF-treated infected mice sustained locomotion at a speed of $14.4 \mathrm{~m} / \mathrm{min}$, but 3 of 7 animals were able to perform at $21.6 \mathrm{~m} / \mathrm{min}$. These differences resulted in significantly greater running times and distances covered by G-CSFtreated mice when compared to saline-treated mice, although G-CSF-treated mice still performed at lower capacity than normal mice (Fig. 5).
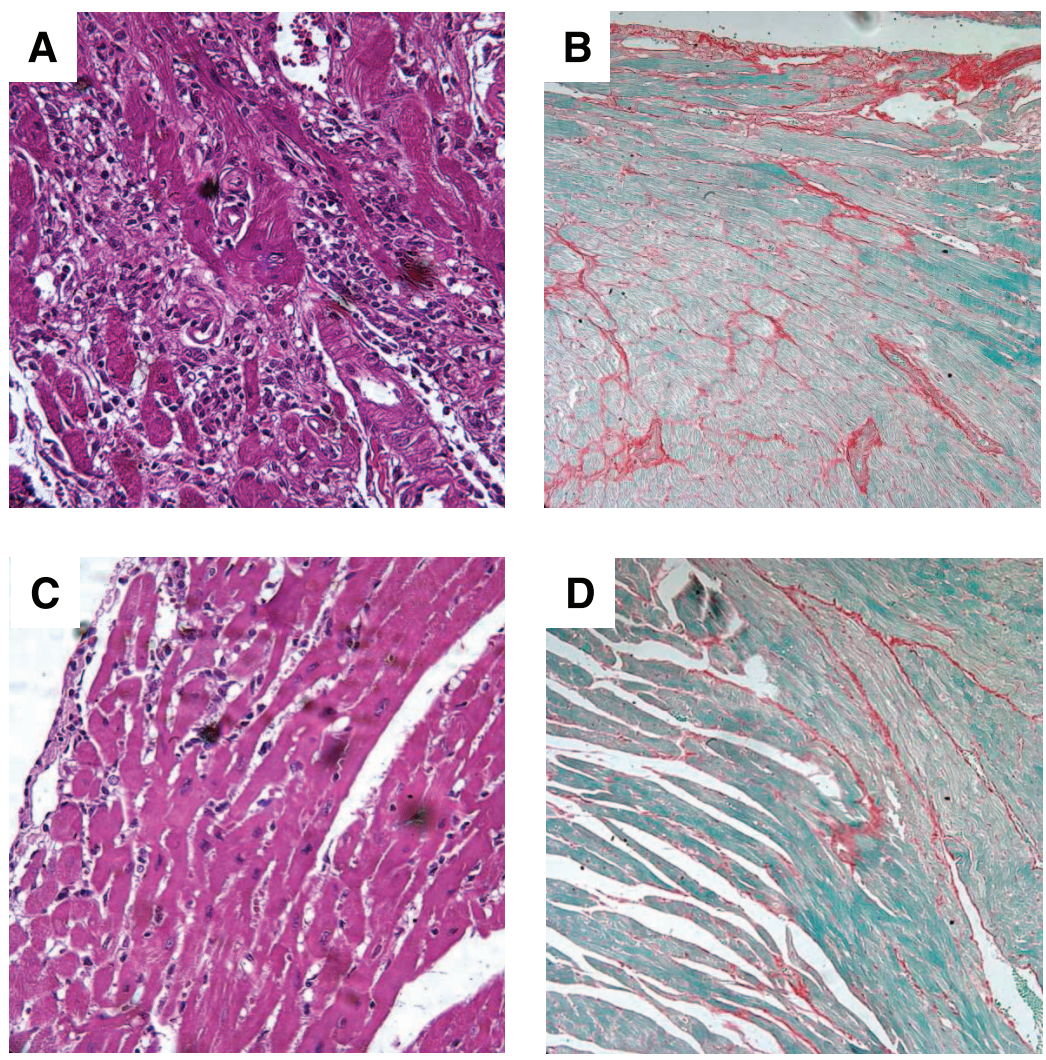

Figure 1. Histopathological analysis in heart sections of T. cruzi-infected mice. Heart sections of saline-treated $(A, C)$ or G-CSF-treated $(B, D)$ T. cruzi-infected mice were analyzed 2 mo after therapy. Staining: H\&E $(A, B ; \times 400)$; Sirius red $(C, D ; \times 200)$. 


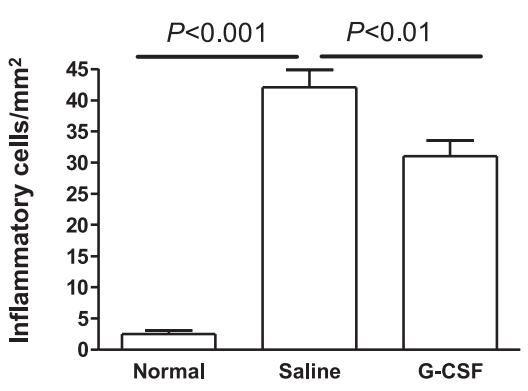

D

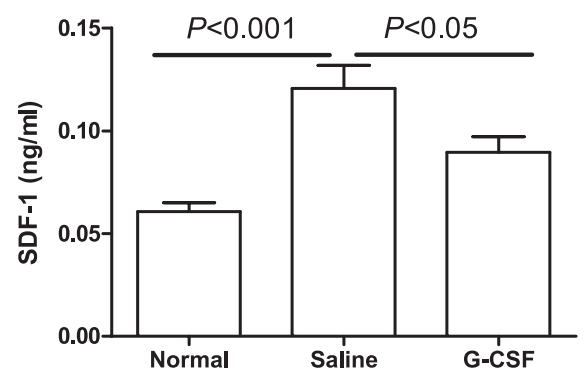

B

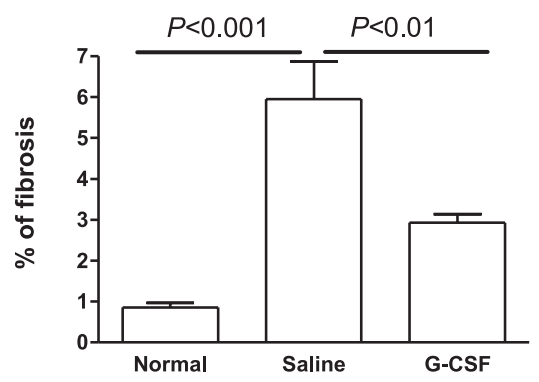

C

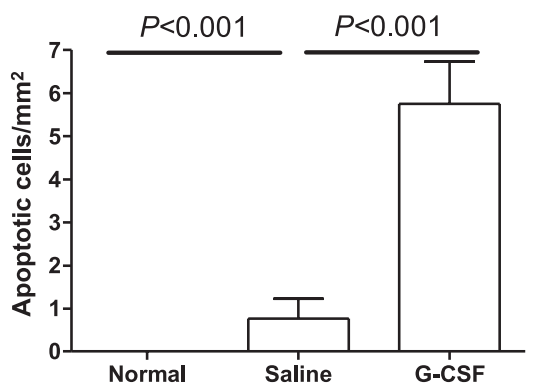

Figure 2. Alterations in inflammation, fibrosis, and SDF-1 production in hearts of G-CSF-treated mice. $A, B$ ) Quantification of inflammatory cells $(A)$ and fibrosis area $(B)$ in heart sections of normal and chagasic mice treated with saline or G-CSF; 6-10 mice/group. C) Numbers of apoptotic inflammatory cells in heart sections were quantified by TUNEL assay; 4 mice/group. D) Levels of SDF-1 in heart homogenates were determined by ELISA; 7-10 mice/group. Values are means $\pm \mathrm{SE}$.

Under resting conditions, the respiratory exchange ratio was significantly different between each group, whereas $\dot{V} \mathrm{O}_{2}$ and $\dot{V} \mathrm{CO}_{2}$ showed no differences (Fig. 6). During exercise stages 1 and $2, \dot{V} \mathrm{CO}_{2}$ was significantly greater in the normal mice compared with G-CSFtreated mice, and respiratory exchange ratio was significantly greater in normal mice at exercise stage 2 when compared with the G-CSF group. Shortly after exercise, $\dot{V} \mathrm{O}_{2}$ and $\dot{V} \mathrm{CO}_{2}$ were significantly greater in normal mice when compared with G-CSF-treated mice, and $\dot{V} \mathrm{CO}_{2}$ remained significantly greater during recovery when compared with both other groups. Within the

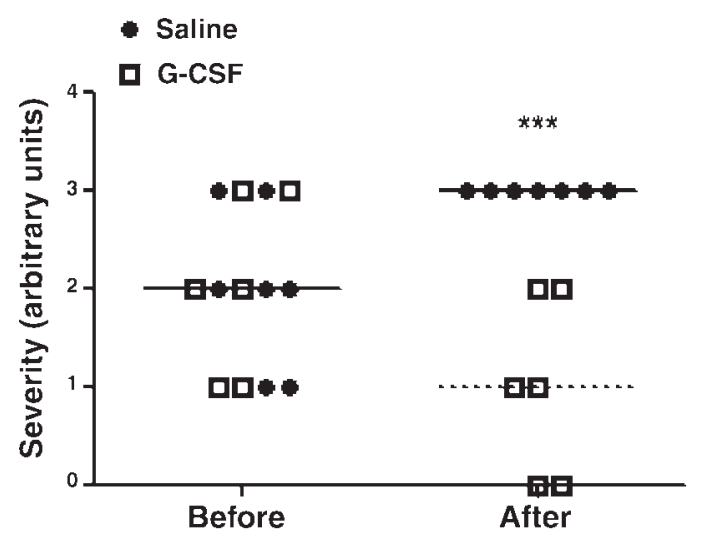

Figure 3. Graph representing cardiac conduction disturbances in arbitrary units in C57BL/6 mice infected with $T$. cruzi before and 2 mo after administration of saline or G-CSF. Degree of severity: 0 , no cardiac conduction disturbances; 1 , first-degree atrium-ventricular block; 2, intraventricular conduction disturbance; 3, atrium-ventricular dissociation; 4, death. Dashed line indicates median of G-CSF treated mice; solid line indicates median in saline-treated mice. Before treatment, both medians are identical. $* * * P<0.001$ between groups after treatment with G-CSF. normal mice, $\dot{V} \mathrm{O}_{2}, \dot{V} \mathrm{CO}_{2}$, and RER rose significantly above resting values during exercise, reaching greatest $\dot{V} \mathrm{O}_{2}$ shortly after cessation of exercise, with decreasing respiratory variables during the recovery phase. The G-CSF-treated mice showed no significant elevation of $\dot{\mathrm{V}} \mathrm{O}_{2}$ and $\dot{\mathrm{V}} \mathrm{CO}_{2}$ during exercise when compared with resting values, but $\dot{V} \mathrm{O}_{2}$ and $\dot{V} \mathrm{CO}_{2}$ shortly after exercise were significantly greater than the values measured during the other stages. Peak oxygen consumption of normal mice $\left(8068 \mathrm{ml} \mathrm{O}_{2} / \mathrm{min} / \mathrm{kg}\right)$ was significantly greater than that of the G-CSF-treated group $(6561 \mathrm{ml}$ $\mathrm{O}_{2} / \mathrm{min} / \mathrm{kg}$ ).

\section{DISCUSSION}

G-CSF is a cytokine known to improve cardiac function and recovery in models of ischemic disease $(7,13,14)$. In this study, we demonstrated that repeated administration of G-CSF induces beneficial effects on cardiac structure, such as reduction of inflammation and fibrosis, that were well correlated with improvements in cardiac function in an experimental model of CChC that closely resembles the human disease $(15,16)$. One may question the low number of infected animals used in this study, and consequently the significance of our results. However, the fact that all of the G-CSF-treated animals improved their performance on the treadmill, when compared with saline-treated mice, shows that G-CSF has a profound effect on chronic chagasic mice. Regarding the cardiac conduction disturbances studied here, 6 of 6 infected animals showed improvements or remained stable due to the G-CSF treatment, whereas all of the saline-treated mice deteriorated; even mice with only a slight first-degree AV blockage evolved 
A

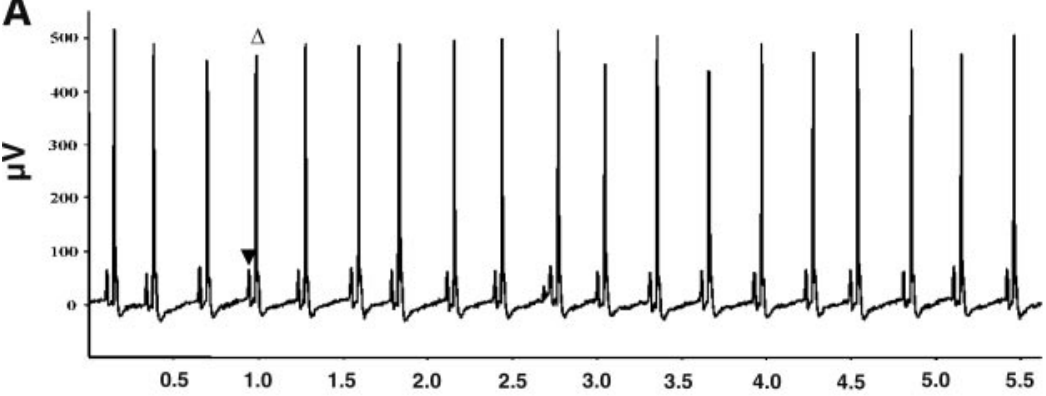

B
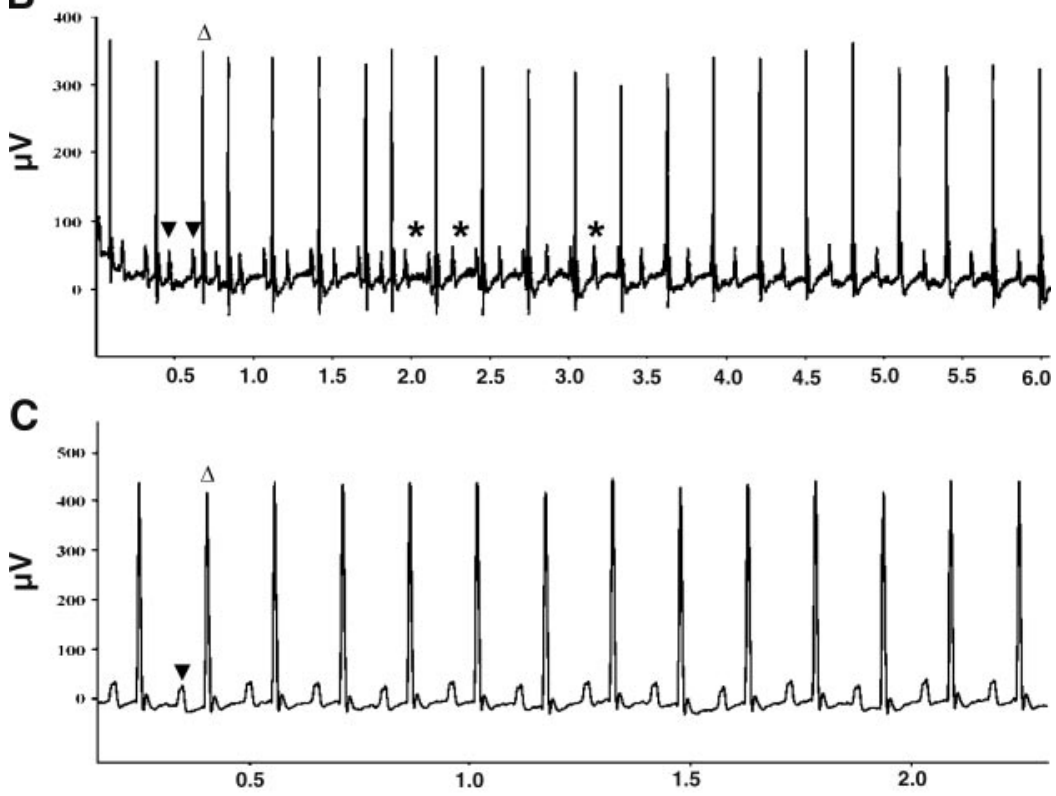

Figure 4. Reversion of cardiac disturbance after G-CSF treatment. ECG of a mouse before infection $(A) ; 6$ mo after infection, before G-CSF treatment $(B)$; and 2 mo after G-CSF treatment (C). $\boldsymbol{\nabla}, \mathrm{P}$ wave; $\triangle$, QRS complex; *, A-V dissociation.

Time (s)

toward an AV dissociation. G-CSF-treated mice, on the other hand, improved cardiac conductance and never surpassed a first-degree AV blockage. These facts, taken together, indicate that G-CSF has a significant therapeutic effect on mice with chronic Chagas disease.

One of the main features of $\mathrm{CChC}$ is the presence of prominent inflammation with participation of an autoimmune component (17-19) that causes destruction of myofibers and fibrosis deposition. We have recently shown that autologous BMC transplant modulates the myocarditis in experimental CChC, an effect associated with apoptosis of inflammatory cells (10). In the current study, we also found that the decreased inflammation after G-CSF therapy correlated with an increase in apoptosis of inflammatory cells. Thus, the benefits of G-CSF therapy may result, in part, from regulation of pathological immune responses. In fact, recent reports have demonstrated that G-CSF inhibits T cells by stimulating apoptosis $(20,21)$.

Heart SDF-1 levels were increased in CChC. The modulation of heart inflammation by G-CSF therapy also correlated with a reduction in SDF-1 in chagasic hearts. This chemokine promotes the recruitment of inflammatory cells, including T cells, and of stem cells, which express its receptor CXCR4 (22), and may play a role in other inflammatory processes in the heart (23,
24). The fact that G-CSF mobilizes stem/precursor cells to the periphery suggests that these cells migrate to the inflamed myocardium and contribute to tissue regeneration, since it has been shown before that mobilized BMSCs repair the damaged myocardium (25). In fact, we have previously found that transplanted BMSCs migrate to and differentiate into cardiomyocytes (10).

Sugano et al. (13) described an accelerated healing process due to increased reparative collagen synthesis in affected areas after G-CSF administration, in an experimental myocardial infarction. A reduction in fibrosis was observed after a long-term treatment using low doses of G-CSF after myocardial infarct (26). Here, we also found a significant reduction in heart fibrosis after G-CSF treatment.

Another feature of chronic Chagas disease is the scarce parasitism found in this phase of infection. Several studies have demonstrated that $T$. cruzi parasites or antigens can be found, although rarely, in individuals with chronic infection $(27,28)$. Although the inflammatory response was modulated after G-CSF therapy, the residual parasite load in our model was not affected by this treatment.

It has been proposed that the main effect of G-CSF after severe cardiac injury is to induce the proliferation of cardiac stem cells rather than BMSC migration and 
A
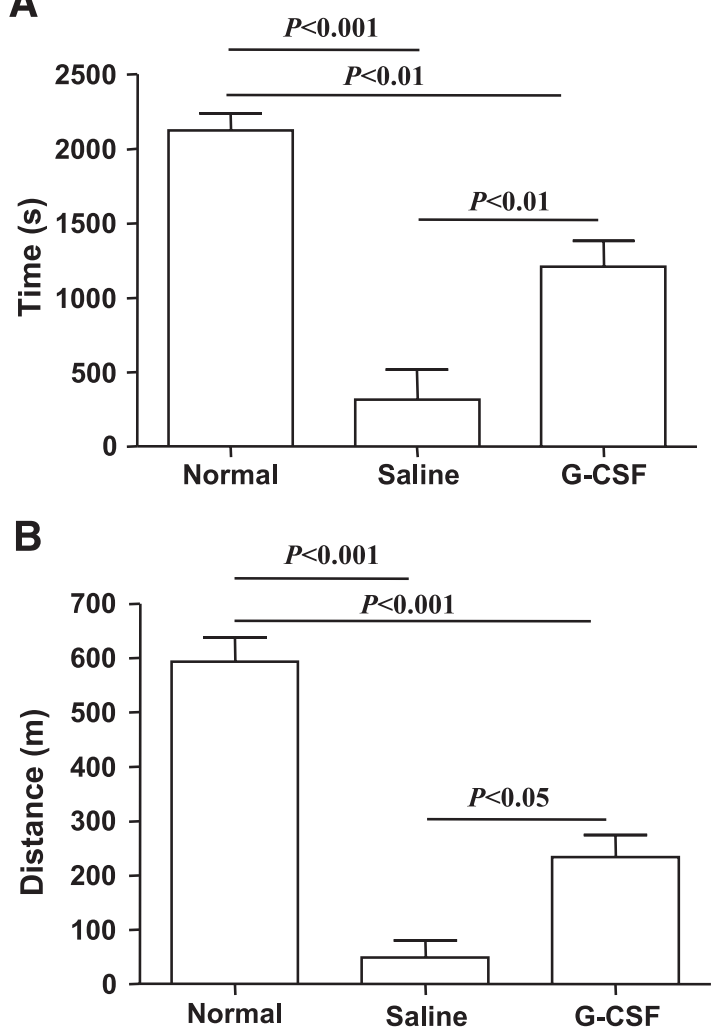

Figure 5. G-CSF treatment improves the capacity of infected mice to perform exercise. Time $(A)$ and distance run $(B)$ on a motorized treadmill by normal (noninfected) mice $(n=10)$ and chronic chagasic mice treated with saline $(n=2)$ or with G-CSF $(n=7)$. Data are means \pm sE. Note that running time and distance of saline-treated mice are highly influenced by 2 of the 6 animals tested that were able to exercise on the treadmill, whereas the other 4 saline-treated animals were not able to run on the treadmill.

proliferation. Kanellakis et al. (29) demonstrated, in a model of acute myocardial infarction, that G-CSF/SCF therapy improved cardiac function, increasing the number of blood vessels and cells of the cardiomyogenic lineage. However, differently from previous studies $(30,31)$, they demonstrated that these cells were of myocardial rather than of bone marrow origin. They also provided evidence that the effects were due to G-CSF alone, since the addition of SCF to G-CSF provided little additional benefit at the functional level. Brunner et al. (32) demonstrated that treatment with G-CSF after myocardial infarct reduces the migratory capacity of bone marrow cells into ischemic tissue, but increases the number of resident cardiac cells.

In our study, we showed that G-GSF administration can avoid the aggravation of cardiac disturbances associated with chronic Chagas disease and, more important, seems to reverse some of the severe pathologies associated with CChC. On the other hand, the untreated group aggravated the cardiac abnormalities. These results were in agreement with other preclinical studies that investigated the antiarrhythmic effects of G-CSF and showed an increase in protein expression levels of $\beta$-catenin and connexin $43(33,34)$. $\beta$-Catenin is necessary to attach many proteins to the cell membrane, including proteins related to gap junction formation. Conexin 43 is responsible for cell-cell communication, and thereby allows the appropriate conduction of cardiac impulses through the whole heart, avoiding arrhythmias. The expression of this protein is reduced by T. cruzi infection (35) and may contribute to the arrhythmias. Thus, the beneficial effects of G-CSF treatment on cardiac electrogenesis may be related to an increase of conexin 43 expression. Kuhlmann et al. (33) proposed that the enhanced expression of G-CSF receptor in cardiomyocytes and other cell types of the

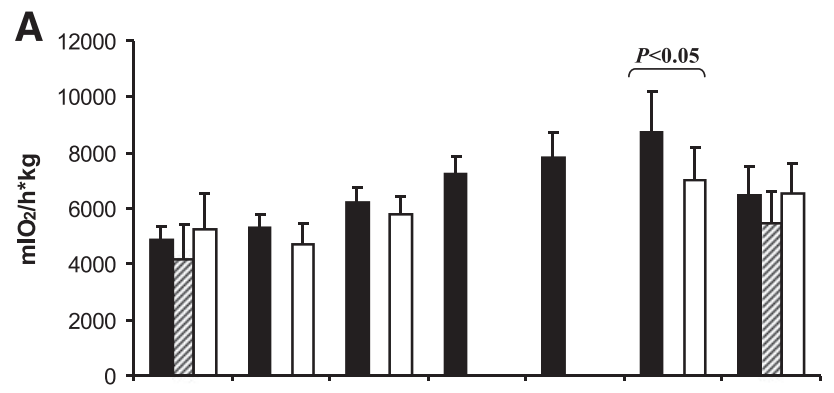

B
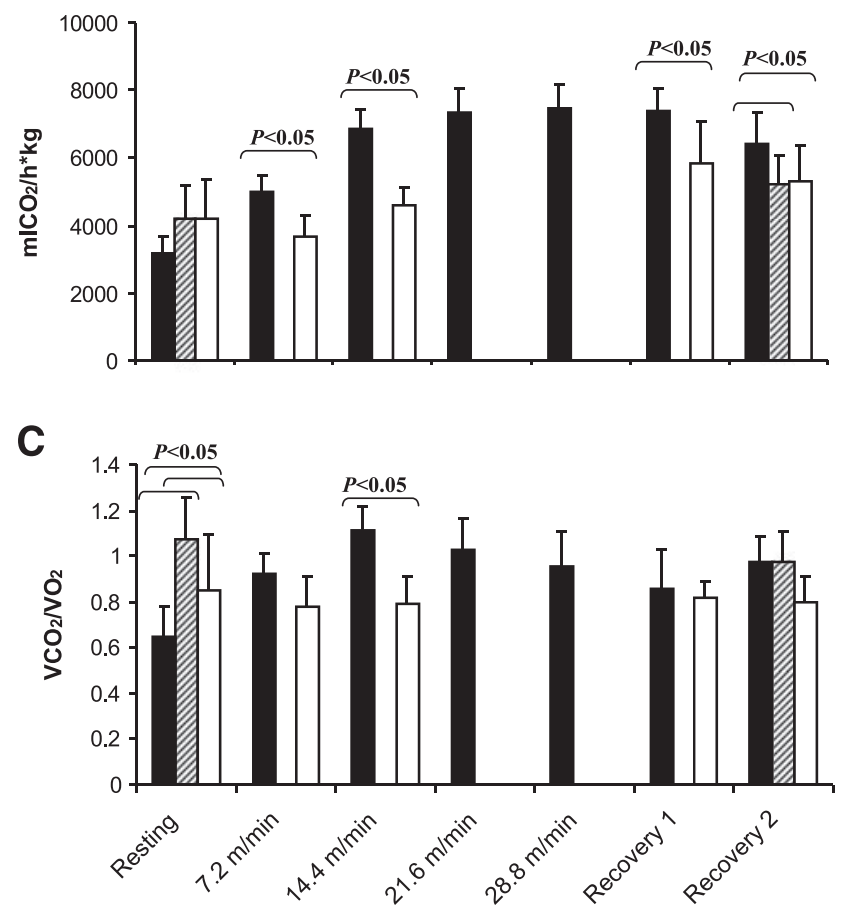

Figure 6. Cardiopulmonary function amelioration during physical effort after G-CSF administration. Oxygen consumption $(A)$, carbon dioxide release $(B)$, and respiratory exchange ratio $(C)$ in normal mice (solid columns), salinetreated chagasic mice (dashed columns), and G-CSF-treated chagasic mice (open columns) during resting conditions, exercising at 4 different velocities $(7.2,14.4,21.6$, and 28.8 $\mathrm{m} / \mathrm{min}$ ) on a motorized treadmill, immediately (recovery 1 ) and $30 \mathrm{~min}$ after exercise (recovery 2 ). Data are means \pm SD; 6-10 mice/group. Note that only 2 of 6 saline-treated infected animals were able to run at a velocity of $14.4 \mathrm{~m} / \mathrm{min}$; therefore, no data are given for saline-treated infected mice during exercise. 
infarcted myocardium indicates a sensitization of the heart to direct influences of this cytokine.

Appropriate cardiac contractility is necessary to allow adjustments of cardiac output during physical exertion, thereby guaranteeing an adequate oxygen supply during any kind of physical effort. In our study, we observed an increase in $\dot{V} \mathrm{O}_{2}$ in G-CSF-treated chagasic mice during exercise, showing values of $\dot{\mathrm{V}} \mathrm{O}_{2}$ similar to the levels reached by the uninfected control group, which indicates adequate adjustments of cardiac output during light exercise regarding oxygen transport. Values of peak $\dot{\mathrm{O}}_{2}$ during exercise, however, where significantly lower in G-CSF mice compared with normal mice, indicating that recovery caused by G-CSF is not complete. Carbon dioxide release, on the other hand, showed a significantly different pattern. Whereas $\dot{V} \mathrm{CO}_{2}$ increased in normal mice at the lower velocities, reaching a plateau in the subsequent exercise velocities and the first recovery period, $\mathrm{CO}_{2}$ release in G-CSFtreated chagasic mice seemed to be significantly impaired. The reasons for such a discrepancy, animals matching their $\dot{\mathrm{V}} \mathrm{O}_{2}$ demands but not being able to appropriately release $\mathrm{CO}_{2}$ during light exercise remain unknown. RER ratio was significantly greater in untreated chagasic mice compared with both other groups. This could be due to a reduced capacity of chagasic mice to carry oxygen to the tissues, resulting in elevated anaerobic metabolism and increased release of $\mathrm{CO}_{2}$. The performance improvement of G-CSF-treated mice can be attributed solely to the beneficial effect of G-CSF on cardiac structure, improving cardiac efficiency.

Li et al. (36) showed that administration of G-CSF in experimental chronic heart failure improved the myocardium contractility by avoiding the systolic and diastolic dysfunction through the changes in the geometry of the infarcted heart to short and thick, induced hypertrophy among surviving cardiomyocytes, and reduced myocardial fibrosis. These effects could be explained by a direct effect of G-CSF on cardiomyocytes that could lead to the activation of an intracellular signal, since the expression of G-CSF receptor was confirmed in failing hearts and was up-regulated by G-CSF treatment $(8,13)$. Our results are in agreement with $\mathrm{Li}$ et al. (36), as G-CSF administration caused a reduction in functional impairment and partial recovery of heart structure.

Chronic heart failure remains a leading cause of mortality due to the absence of an efficient therapy that avoids structural and electrical cardiac remodeling. The only option for these patients remains heart transplantation. Besides limitations of available donated organs, in the specific case of Chagas disease, the use of immunosupressive drugs following heart transplantation can affect the latent parasitism. On the basis of the beneficial effects of G-CSF shown in the present study, we conclude that this may be a promising therapy for the treatment of patients with heart failure due to Chagas disease. An ongoing phase I/II clinical trial of G-CSF therapy with multiple administrations in cha- gasic patients (37) may indicate the benefits of this therapy in humans.

This work was supported by grants from the Brazilian Ministry of Science and Technology [Conselho Nacional de Desenvolvimento Científico e Tecnológico (CNPq)], Financiadora de Estudos e Projetos (FINEP), Fiocruz, and Fundação de Amparo à Pesquisa do Estado da Bahia (FAPESB).

\section{REFERENCES}

1. Orlic, D., Kajstura, J., Chimenti, S., Jakoniuk, I., Anderson, S. M., Li, B., Pickel, J., McKay, R., Nadal-Ginard, B., Bodine, D. M., Leri, A., and Anversa, P. (2001) Bone marrow cells regenerate infarcted myocardium. Nature 410, 701-705

2. Orlic, D., Kajstura, J., Chimenti, Limana, S., F., Jakoniuk, I., Quaini, F., Nadal-Ginard, B., Bodine, D. M., Leri, A., and Anversa, P. (2001) Mobilized bone marrow cells repair the infarcted heart, improving function and survival. Proc. Natl. Acad. Sci. U. S. A. 98, 10344-10349

3. Assmus, B., Schächinger, V., Teupe, C., Britten, M., Lehmann, R., Döbert, N., Grünwald, F., Aicher, A., Urbich, C., Martin, H., Hoelzer, D., Dimmeler, S., and Zeiher, A. M. (2002) Transplantation of progenitor cells and regeneration enhancement in acute myocardial infarction. Circulation 106, 3009-3017

4. Perin, E. C., Dohmann, H. F. R., Borojevic, Silva, R. S. A., Sousa, A. L. S., Mesquita, C. T., Rossi, M. I. D., Carvalho, A. C., Dutra, H. S., Dohmann, H. J. F., Silva, G. V., Belém, L., Vivacqua, R., Rangel, F. O. D., Esporcatte, R., Geng, Y. J., Vaughn, W. K., Assad, J. A. R., Mesquita, E. T., and Willerson, J. T. (2003) Transendocardial, autologous bone marrow cell transplantation for severe, chronic ischemic heart failure. Circulation 107, 22942302

5. Clark, S. C., Kamen, R. (1987) The human hematopoietic colony-stimulating factors. Science 236, 1229-1237

6. Tanaka, J., Miyake, T., Shimizu, T., Wakayama, T., Tsumori, M., Koshimura, K., Murakami, Y., and Kato, Y. (2002) Effect of continuous subcutaneous administration of a low dose of G-CSF on stem cell mobilization in healthy donors: a feasibility study. Int. J. Hematol. 75, 489-492

7. Iwanaga, K., Takano, H., Ohtsuka, M., Hasegawa, H., Zou, Y., Qin, Y., Odaka, K., Hiroshima, K., Tadokoro, H., and Komuro, I. (2004) Effects of G-CSF on cardiac remodeling after acute myocardial infarction in swine. Biochem. Biophys. Res. Commun. 325, 1353-1359

8. Harada, M., Qin, Y., Takano, H., Minamino, T., Zou, Y., Toko, H., Ohtsuka, M., Matsuura, K., Sano, M., Nishi, J., Iwanaga, K., Akazawa, H., Kunieda, T., Zhu, W., Hasegawa, H., Kunisada, K. Nagai, T., Nakaya, H., Yamauchi-Takihara, K., and Komuro, I (2005) G-CSF prevents cardiac remodeling after myocardial infarction by activating the Jak-Stat pathway in cardiomyocytes. Nat. Med. 11, 305-311

9. Fujita, J., Mori, M., Kawada, H., Ieda, Y., Tsuma, M., Matsuzaki, Y., Kawaguchi, H., Yagi, T., Yuasa, S., Endo, J., Hotta, T., Ogawa, S., Okano, H., Yozu, R., Ando, K. and Fukuda, K. (2007) Administration of granulocyte colony-stimulating factor after myocardial infarction enhances the recruitment of hematopoietic stem cell-derived myofibroblasts and contributes to cardiac repair. Stem Cells 25, 2750-2759

10. Soares, M. B., Lima, R. S., Rocha, L. L., Takyia, C. M., Pontesde-Carvalho, L., Campos de Carvalho, A. C., and Ribeiro-dosSantos, R. (2004) Transplanted bone marrow cells repair heart tissue and reduced myocarditis in chronic chagasic mice. Am. J. Pathol. 164, 441-447

11. Federici, E. E., Abelmann, W. B., and Neva, F. A. (1964) Chronic and progressive myocarditis in CH3 mice infected with Trypanosoma cruzi. Am. J. Trop. Med. Hyg. 13, 272-280

12. Brener, Z. (1973) Biology of Trypanosoma cruzi. Ann. Rev. Microbiol. 27, 347-382

13. Sugano, Y., Anzai, T., Yoshikawa, T., Maekawa, Y., Kohno, T., Mahara, K., Naito, K., and Ogawa, S. (2005) Granulocyte colony-stimulating factor attenuates early ventricular expansion 
after experimental myocardial infarction. Cardiovasc. Res. 65, $446-456$

14. Deindl, E., Zaruba, M. M., Brunner, S., Huber, B., Mehl, U., Assmann, G., Hoefer, I. E., Mueller-Hoecker, J., and Franz, W. M. (2006) G-CSF administration after myocardial infarction in mice attenuates late ischemic cardiomyopathy by enhanced arteriogenesis. FASEB J. 20, 27-36

15. Soares, M. B., Silva-Mota, K. N., Lima, R. S., Bellintani, M. C., Pontes-de-Carvalho, L., and Ribeiro-dos-Santos, R. (2001) Modulation of chagasic cardiomyopathy by interleukin-4: dissociation between inflammation and tissue parasitism. Am. J. Pathol. 159, 703-709

16. Rocha, N. N., Garcia, S., Giménez, L. E., Hernández, C. C., Senra, J. F., Lima, R. S., Cyrino, F., Bouskela, E., Soares, M. B., Ribeiro-dos-Santos, R., and Campos de Carvalho A. C. (2006) Characterization of cardiopulmonary function and cardiac muscarinic and adrenergic receptor density adaptation in C57BL/6 mice with chronic Trypanosoma cruzi infection. Parasitology 133, 729-737

17. Pontes-de-Carvalho, L., Santana, C. C., Soares, M. B., Oliveira, G. G., Cunha-Neto, E., and Ribeiro-dos-Santos, R. (2002) Experimental chronic Chagas' disease myocarditis is an autoimmune disease preventable by induction of immunological tolerance to myocardial antigens. J. Autoimmun. 18, 131-138

18. Soares, M. B., Pontes-de-Carvalho, L., and Ribeiro-dos-Santos, R. (2001) The pathogenesis of Chagas' disease: when autoimmune and parasite-specific immune responses meet. An. Acad. Bras. Cienc. 73, 547-559

19. Leon, J. S., Godsel, L. M., Wang, K., and Engman, D. M. (2001) Cardiac myosin autoimmunity in acute Chagas' heart disease. Infect. Immun. 69, 5643-5649

20. Rutella, S., Pierelli, L., and Rumi, C. (2001) T-cell apoptosis induced by granulocyte colony-stimulating factor (G-CSF) is associated with retinoblastoma protein phosphorylation and reduced expression of cyclin-dependent kinase inhibitors. Exp. Hematol. 29, 401-415

21. Rutella, S., Pierelli, L., Bonanno, G., Sica, S., Ameglio, F., Capoluongo, E., Mariotti, A., Scambia, G., d'Onofrio, G., and Leone. G. (2002) Role for granulocyte colony-stimulating factor in the generation of human T regulatory type 1 cells. Blood $\mathbf{1 0 0}$ 2562-2571

22. Vandervelde, S., van Luyn, M. J., Tio, R. A., and Harmsen, M. C. (2005) Signaling factors in stem cell-mediated repair of infarcted myocardium. J. Mol. Cell. Cardiol. 39, 363-376

23. Wojakowski, W., Tendera, M., Michałowska, A., Majka, M. Kucia, M., Maślankiewicz, K., Wyderka, R., Ochała, A., and Ratajczak, M. Z. (2004) Mobilization of CD34/CXCR4+, CD34/ CD117+, c-met + stem cells, and mononuclear cells expressing early cardiac, muscle, and endothelial markers into peripheral blood in patients with acute myocardial infarction. Circulation 110, 3213-3220

24. Mieno, S., Ramlawi, B., Boodhwani, M., Clements, R. T., Minamimura, K., Maki, T., Xu, S. H., Bianchi, C., Li, J., and Sellke, F. W. (2006) Role of stromal-derived factor- $1 \alpha$ in the induction of circulating CD34+CXCR4+ progenitor cells after cardiac surgery. Circulation 114, I186-I192

25. Fukuhara, S., Tomita, S., Nakatani, T., Ohtsu, Y., Ishida, M., Yutani, C., and Kitamura, S. (2004) G-CSF promotes bone marrow cells to migrate into infarcted mice heart, and differentiate into cardiomyocytes. Cell Transplant. 13, 741-748
26. Okada, H., Takemura, G., Li, Y., Ohno, T., Li, L., Maruyama, R., Esaki, M., Miyata, S., Kanamori, H., Ogino, A., Nakagawa, M., Minatoguchi, S., Fujiwara, T., and Fujiwara, H. (2008) Effect of a long-term treatment with a low-dose granulocyte colonystimulating factor on post-infarction process in the heart. J. Cell. Mol. Med. 12, 1272-1283

27. Jones, E. M., Colley, D. G., Tostes, S., Lopes, E. R., VnencakJones, C. L., and McCurley, T. L. (1993) Amplification of a Trypanosoma cruzi DNA sequence from inflammatory lesions in human chagasic cardiomyopathy. Am. J. Trop. Med. Hyg. 48, 348-357

28. Palomino, S. A., Aiello, V. D., and Higuchi, M. L. (2000) Systematic mapping of hearts from chronic chagasic patients: the association between the occurrence of histopathological lesions and Trypanosoma cruzi antigens. Ann. Trop. Med. Parasitol. 94, 571-579

29. Kanellakis, P., Slater, N. J., Du, X. J., Bobik, A., and Curtis, D. J. (2006) Granulocyte colony-stimulating factor and stem cell factor improve endogenous repair after myocardial infarction. Cardiovasc. Res. 70, 117-125

30. Laflamme, M. A., Myerson, D., Saffitz, J. E., and Murry, C. E. (2002) Evidence for cardiomyocyte repopulation by extracardiac progenitors in transplanted human hearts. Circ. Res. 90, 634-640

31. Müller, P., Pfeiffer, P., Koglin, J., Schäfers, H. J., Seeland, U., Janzen, I., Urbschat, S., and Böhm. M. (2002) Cardiomyocytes of noncardiac origin in myocardial biopsies of human transplanted hearts. Circulation 106, 31-35

32. Brunner, S., Huber, B. C., Fischer, R., Groebner, M., Hacker, M., David, R., Zaruba, M. M., Vallaster, M., Rischpler, C., Wilke, A., Gerbitz, A., and Franz, W. M. (2008) G-CSF treatment after myocardial infarction: Impact on bone marrow derived vs cardiac progenitor cells. Exp. Hematol. 36, 695-702

33. Kuhlmann, M. T., Kirchhof, P., Klocke, R., Hasib, L., Stypmann, J., Fabritz, L., Stelljes, M., Tian, W., Zwiener, M., Mueller, M., Kienast, J., Breithardt, G., and Nikol, S. (2006) G-CSF/SCF reduces inducible arrhythmias in the infarcted heart potentially via increased connexin 43 expression and arteriogenesis. J. Exp. Med. 203, 87-97

34. Kuwabara, M., Kakinuma, Y., Katare, R. G., Ando, M., Yamasaki, F., Doi, Y., and Sato, T. (2007) Granulocyte colony-stimulating factor activates Wnt signal to sustain gap junction function through recruitment of $\beta$-catenin and cadherin. FEBS Lett. 581, 4821-4830

35. Adesse, D., Garzoni, L. R., Huang, H., Tanowitz, H. B., de Nazareth Meirelles, M., and Spray, D. C. (2008) Trypanosoma cruzi induces changes in cardiac connexin43 expression. $M i$ crobes Infect. 10, 21-28

36. Li, Y., Takemura, G., Okada, H., Miyata, S., Esaki, M., Maruyama, R., Kanamori, H., Li, L., Ogino, A., Misao, Y., Khai, N. C., Mikami, A., Minatoguchi, S., Fujiwara, T., and Fujiwara, H. (2006) Treatment with granulocyte colony-stimulating factor ameliorates chronic heart failure. Lab. Invest. 86, 32-44

37. Soares, M. B., Garcia, S., Campos de Carvalho, A. C., and Ribeiro-dos-Santos, R. (2007) Cellular therapy in Chagas' disease: potential applications in patients with chronic cardiomyopathy. Regen. Med. 2, 257-264

Received for publication June 1, 2009 Accepted for publication June 25, 2009. 